\title{
Research on "Subsidy Defraud" of New Energy Vehicles Enterprises Based on Signal Game
}

\author{
Xi Tang1*, Junmin Wu' ${ }^{1}$ Bo Feng ${ }^{2}$, Xiaozhuo Wei', Xiangyu Mao', Weiyi Shao ${ }^{3}$ \\ ${ }^{1}$ School of Economics and Management, Jiangsu University of Science and Technology, Zhenjiang, China \\ ${ }^{2}$ School of Management, Nanjing Audit University Jinshen College, Nanjing, China \\ ${ }^{3}$ Zhenjiang Audit Bureau, Zhenjiang, China \\ Email: *1763918419@qq.com
}

How to cite this paper: Tang, $\mathrm{X}$., $\mathrm{Wu}$, J.M., Feng, B., Wei, X.Z., Mao, X.Y. and Shao, W.Y. (2019) Research on "Subsidy Defraud" of New Energy Vehicles Enterprises Based on Signal Game. Open Journal of Business and Management, 7, 1803-1814. https://doi.org/10.4236/ojbm.2019.74124

Received: September 2, 2019

Accepted: September 24, 2019

Published: September 27, 2019

Copyright $\odot 2019$ by author(s) and Scientific Research Publishing Inc. This work is licensed under the Creative Commons Attribution International License (CC BY 4.0).

http://creativecommons.org/licenses/by/4.0/

\begin{abstract}
New energy vehicle subsidy is an important way for our government to support new energy vehicle industry. In recent years, our government has formulated a policy of vigorously supporting the new energy automobile industry. With the increase of support, the number of new energy vehicles in China has increased year by year. In view of the information asymmetry between the government and the enterprise in the implementation of the new energy vehicle subsidies policy, this paper studies the problem of the reverse selection of the enterprise and the government in the subsidy process by using the signal game model, and analyzes the related influencing factors and the game equilibrium. The results show that the probability of "subsidy defraud" is greatly improved due to the asymmetry of information between enterprises and governments. Realize the optimal separation and equilibrium solution of high sales enterprises applying for high subsidies and the government giving high subsidies; low sales enterprises apply for low subsidies, and the government gives the optimal separation equilibrium solution of low subsidies. It is necessary to increase the camouflage cost of the enterprise's "subsidy defraud" and to increase the punishment of the "subsidy defraud". At the same time, according to the results of the study, the relevant suggestions and countermeasures of the government's preventive "subsidy defraud" behavior are put forward. The above research is of great theoretical significance and practical value in promoting the development of new energy vehicles in the post-subsidy era.
\end{abstract}

\section{Keywords}

Signal Game, New Energy Vehicles, Enterprise Sales, Government Subsidy

\section{Introduction}

The "green development" is highlighted in the 19th CPC National Congress re- 
port, which is in need of a revolutionary change in the automotive industry of China's national economy. New energy vehicle uses unconventional vehicle fuel as power source [1], and uses advanced vehicle power control technology and driving technology to manufacture [2], It has the characteristics of low fuel consumption and low emission [3], which is completely in line with the theme of "green development" in the future of our country, and has become an important part of the transformation and development of automobile in our country. In the "The Thirteenth Five-Year Plan", it is proposed that in order to continue to implement the new energy vehicle promotion plan, it is necessary to further strengthen the structural transformation of the traditional fuel vehicle industry through the regulation and support of the government.

In order to promote the development of the new energy vehicle industry, the central and local governments have successively issued a series of incentive industrial development policies such as vehicle purchase subscriptions, tax preference, bus procurement, etc. However, many enterprises fabricate false material procurement, vehicle production and sales and other original vouchers and records, fictitious sales business to defraud the government subsidy for their own benefit. This kind of behavior not only reduces the incentive benefit of the government subsidy to the new energy vehicle industry, but also reduces the enthusiasm of the production and development of the formal manufacturers, which greatly hinders the development of the whole new energy vehicle industry. If the above-mentioned problems cannot be solved in a timely and reasonable manner, the development of the new energy vehicle industry in China will be in trouble.

\section{Review of Literature}

Subsidy is a direct or indirect material transfer to an enterprise or individual by the government free of charge. At present, the relevant scholars at home and abroad have made a great deal of research on the problem of subsidy. In the early stages of the development of new energy vehicle, Dogan Keles et al. [4] proposed that only by conducting fiscal and tax subsidy and infrastructure construction subsidy could we better reduce the cost of new energy vehicle and promote the development of industry. Richard [5] found that by studying the asymmetry of information that could lead to the weakening of the government's subsidy effect, the government must take relevant measures to avoid the problem. Li lei [6] used innovation ecology theory and population relation theory to study new energy vehicle government subsidy and pointed out that government research and development subsidy is positively related to innovation in industry. Shao Wei, et al. [7] divides the government subsidy into two categories: the production of subsidy and R \& D subsidy, and the conclusion that $\mathrm{R} \& \mathrm{D}$ subsidy's incentive to new energy vehicle enterprises is much higher than that of the production of subsidy. Ma Liang and Zhong Weijun [8], based on the coordination of the new energy vehicle industry chain, have studied the optimal strategy 
choice of the battery manufacturers and auto manufacturers in the new energy vehicle industry chain by using the integration of the industrial chain and the independent decision-making, and put forward relevant suggestions to improve the battery life of the new energy vehicle.

Because in subsidy, factors such as policy, manner and intensity will have a huge impact on production decisions. The development of enterprises, marketing performance will also affect the formulation of government subsidy policy. Therefore, the relationship between enterprises and governments can be described as a multi-party game process, so game theory has been widely used in new energy vehicle subsidies problems.

Through the combing of the literature, it can be found that the game research of new energy vehicle subsidies can be roughly divided into the following two kinds. First, the influence factor analysis is carried out while the process of the new energy vehicle subroutines is abstracted. For example, Zhong Taiyong and Du Rong [9] used the signal game model to abstract the process of subsidy, and studied the problem of the new energy vehicle and the government in subsidy. Cao Feishao and Wu Di [10] use the signal game model to obtain the conclusion that the key condition to realize the complete success of the market is to improve the risk cost of the enterprise's "subsidy defraud". Wang Haixiao and Miao Xiaoming [11] prove that the information asymmetry can have a negative impact on the development of new energy vehicle industry by using the complete information static and incomplete information dynamic model, and the relevant suggestions are put forward. The second is to use the evolutionary game to analyze the new energy vehicle subsides. For example, Cao Guohua and Yang Junjie [12] used the evolutionary game model to study the game relationship between the government and the consumers, and put forward relevant suggestions. Xie Meng and Pang Shoulin [13] conducted a study on the new energy vehicle government subsidy by using the option game and the evolutionary game, and the conclusion that different types of subsidy should be given to the government at different stages of the development of the new energy vehicle industry. Based on the evolutionary game model, Sun Hongxia and Lv Huirong [14] elaborated the behavior relation between the enterprise and the government on the premise of the weakening of the new energy vehicle subsides, and put forward the relevant suggestions through the parameter simulation. Zuping $\mathrm{Hu}$ [15] according to the characteristics of dynamic game of incomplete information between government and enterprises in the process of implementing and applying for subsidies, this paper constructs a signaling game model between government and enterprises and puts forward relevant policy suggestions in order to provide theoretical reference and guidance for the new energy automobile subsidy policy. Liu Minjian [16] establishing a signaling game model, this paper studies the strategy selection in the process of government and automobile subsidies, and makes an analysis of the game equilibrium.

Although the game theory is widely used in the new energy vehicle subsides, 
the majority of scholars only pay attention to the effect of the subsidy policy on the new energy vehicle industry, and the research on the "subsidy defraud" behavior is relatively small. Therefore, using signal game model, this paper abstracts the process of enterprise applying for subsidy and government issuing subsidy, theoretically studies the decision choice of enterprise and government, and provides relevant countermeasures and suggestions for how to avoid the occurrence of "subsidy defraud" behavior.

\section{Construction of Signal Game Model}

\subsection{Construction of Game}

Signal game refers to a game in which two participants, the sender sends out private information and the receiver makes decisions on the basis of receiving the sender's information.

Construction of game model:

1) There are two players in the game: new energy vehicle enterprise and government.

2) In this game model, the new energy vehicle enterprise is the sender $A$ of the signal, and the government is the receiver $B$ of the signal. The government hopes to promote the development of the new energy vehicle industry and increase the social benefits through government subscription. New energy vehicle companies are hoping to get more subsidies to increase corporate efficiency. Because the government doesn't know the real research and development ability of the enterprise, the production and operation ability, so the information of both sides is not symmetrical, can be solved by signal game.

Note: new energy vehicle is divided into two categories: high sales and low sales. This is because the "subsidy defraud" behavior of the enterprise is made by making up the original vouchers and records of the procurement of false materials and the production and sale of the vehicles, and make up the fictitious sales business.

\subsection{Game Logic}

1) "Nature" selects the type of enterprise, that is, the type of $A$, according to a certain probability, this $A=\{H, L\}$. Among them, represents the high sales in the new energy vehicle industry and $L$ represents the low sales in the new energy vehicle industry. The probabilities of the two are $p(H)$ and $p(L)$, and $p(H)+p(L)=1$, respectively.

2) The new energy vehicle enterprise $A$ chooses a behavior in the behavior space $\theta=\left\{V_{h}, V_{l}\right\}$ after understanding its type. Among them, $V_{h}$ representative applied for high subsidy, $V_{l}$ representative applied for low subsidy, and $V_{h}>V_{l}$.

3) The government $B$, as the recipient of the signal, uses the Bayesian formula to correct the prior probability, and obtains the posterior probability of the specific sales type of the new energy vehicle enterprise, and selects the own strategy 
according to the subsequent check probability. The government has three strategic choices, that is.

4) $K_{H}-V_{H}>K_{L}-V_{L}$, here represents the enterprise in the high sales volume when the social welfare is higher.

5) $p\left(H \mid V_{H}\right)$ represents the posterior probability of high-sales enterprises when the enterprise applies for high subsidy.

$p\left(L \mid V_{H}\right)$ represents the posterior probability of a low-volume enterprise when the enterprise applies for a high subsidy.

$p\left(L \mid V_{L}\right)$ represents the posterior probability of a low-volume enterprise when the enterprise application is low.

This paper assumes that companies with high sales only apply for high subsidy, so $p\left(H \mid V_{H}\right)=1, p\left(H \mid V_{L}\right)=0, p\left(L \mid V_{H}\right)+p\left(L \mid V_{L}\right)=1$.

6) Enterprises with low sales volume should camouflage when applying for high subsidy, and set the camouflage cost as $C$. If the "subsidy defraud" behavior of the enterprise is discovered by the government department, $W$ will be punished and the probability of being found is $\alpha(0<\alpha<1)$.

7) When the high-sales enterprise is rejected, the production enthusiasm of the enterprise can be reduced, which is not conducive to the development of the new energy vehicle industry, so that the social benefit $Z_{1}$ can be reduced. When a high-selling enterprise is given a low level, the social benefit $Z_{2}$ is reduced. When companies with low sales are rejected, subsidy, social benefits $Z_{3}$ will be reduced and $Z_{1}>Z_{2}>Z_{3}$.

8) When low-selling enterprises are given high subsidy, it will drive the "subsidy defraud" atmosphere of the whole industry and reduce social $Z_{4}$. Here, because the new energy vehicle industry is still in an emerging stage, once the "subsidy defraud" atmosphere spreads to the entire industry, the losses will be inestimable and $Z_{4}>Z_{1}>Z_{2}>Z_{3}$.

9) The production and management of new energy vehicle enterprises will bring benefits to enterprises $S_{i}(i=H, L)$ and $S_{H}>S_{L}$.

\subsection{The Main Parameters of the Model and Its Meaning}

According to the above discussion, the main parameters and their meanings of the model are summarized (Table 1).

Table 1. Main parameters and meanings of the model.

\begin{tabular}{cl}
\hline parameter & \multicolumn{1}{c}{ Meaning } \\
\hline$p(H)$ & Probability of High Sales Enterprises in New Energy Automobile Industry \\
$p(L)$ & Probability of Low Sales Enterprises in New Energy Automobile Industry \\
$V_{H}$ & High subsidy quota \\
$V_{L}$ & low subsidy quota \\
$K_{H}$ & Social Benefits of High Sales Enterprises \\
$K_{L}$ & Social Benefits of Low Sales Enterprises \\
\hline
\end{tabular}




\section{Continued}

\begin{tabular}{cl}
\hline$S_{H}$ & Sales Profits of High Sales Enterprises \\
$S_{L}$ & Sales Profits of Low Sales Enterprises \\
$W$ & Camouflage cost \\
$\alpha$ & $\begin{array}{l}\text { Penalties imposed on enterprises after the detection of fraudulent } \\
\text { compensation }\end{array}$ \\
$p\left(H / V_{H}\right)$ & $\begin{array}{l}\text { Probability of detection of fraud } \\
\text { Tigh Subsidies }\end{array}$ \\
$p\left(H / V_{L}\right)$ & $\begin{array}{l}\text { The Posterior Probability of Enterprises with High Sales in Applying for Low } \\
\text { Subsidies }\end{array}$ \\
$p\left(L / V_{H}\right)$ & $\begin{array}{l}\text { The Posterior Probability of Enterprises with Low Sales in Applying for High } \\
\text { Subsidies }\end{array}$ \\
$Z_{1}$ & $\begin{array}{l}\text { The Posterior Probability of Low Sales Enterprises Applying for Low Subsidies } \\
Z_{2}\end{array}$ \\
$Z_{3}$ & $\begin{array}{l}\text { Social Benefits of High Sales Enterprises Given Low Subsidies Loss } \\
Z_{4}\end{array}$
\end{tabular}

So to sum up, the game tree is shown in the following figure:

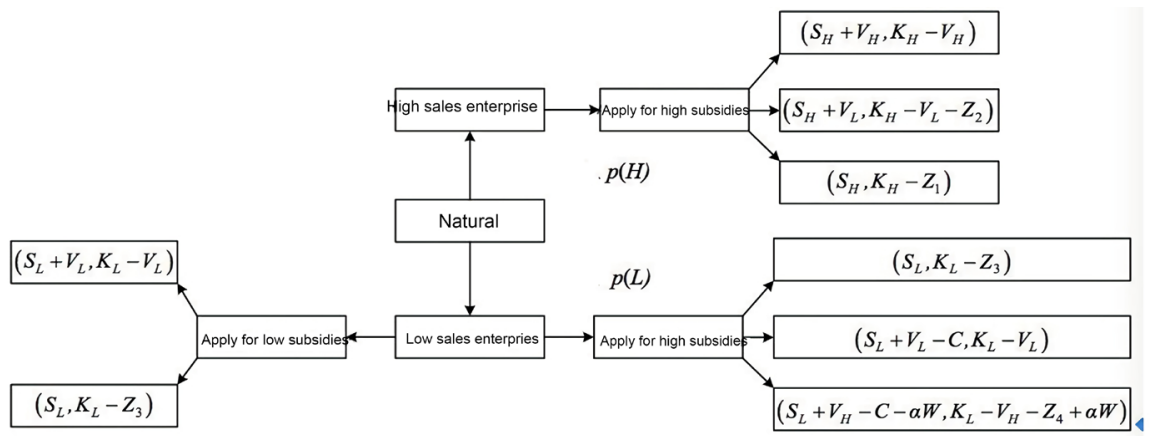

\section{Solution of Signal Game Model}

"Separation" and "confusion" are both classifications of games. In the type of "separated game", participants with different private information can choose different equilibrium strategies to achieve "group by group", while mixed equilibrium only has exactly the same strategy. Therefore, the analysis of signal game from these two perspectives makes the conclusion more perfect and comprehensive.

\subsection{Solution and Analysis of Mixed Equilibrium}

First of all, we consider mixed equilibrium. Companies with high/low sales have applied for high subsidy. The government has chosen to give high subsidy. The game tree is shown in the following figure: 


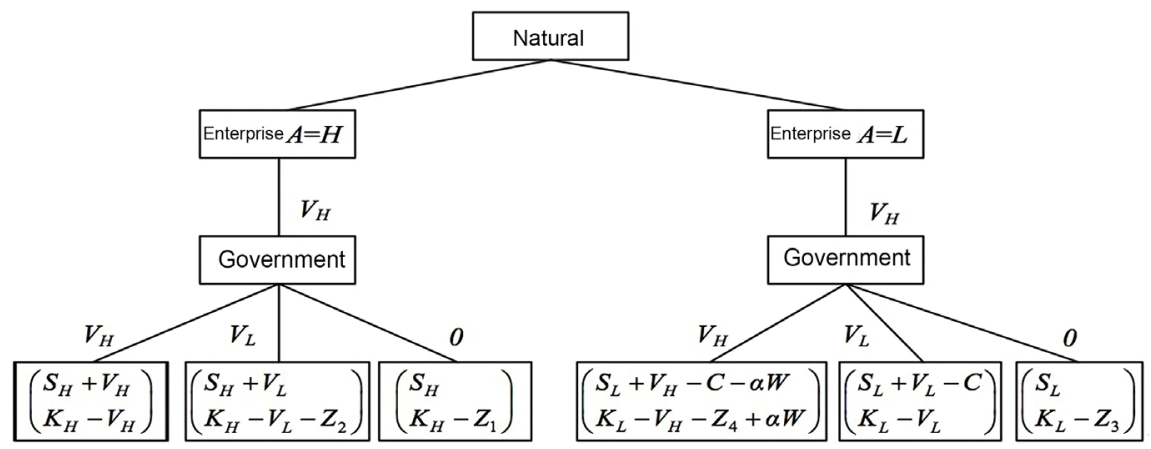

In the second stage of the game, the government forms a judgment on the real sales volume of the enterprise based on the $V_{H}$, received: $p\left(H \mid V_{H}\right)=p$, $p\left(L \mid V_{H}\right)=1-p$. According to the judgment, select the action $\left\{V_{H}, V_{L}, 0\right\}$, maximize their own expected profits, that is:

$$
\begin{aligned}
\max & \left\{p\left(K_{H}-V_{H}\right)+(1-p)\left(K_{L}-V_{H}-Z_{4}+\alpha W\right), p\left(K_{H}-V_{L}-Z_{2}\right)\right. \\
& \left.+(1-p)\left(K_{L}-V_{L}\right), p\left(K_{H}-Z_{1}\right)+(1-p)\left(K_{L}-Z_{3}\right)\right\}
\end{aligned}
$$

The necessary and sufficient condition for the government to choose the $V_{H}$ (that is, give high subsidy) is:

$$
\begin{aligned}
& p\left(K_{H}-V_{H}\right)+(1-p)\left(K_{L}-V_{H}-Z_{4}+\alpha W\right) \\
& >p\left(K_{H}-V_{L}-Z_{2}\right)+(1-p)\left(K_{L}-V_{L}\right)
\end{aligned}
$$

and

$$
p\left(K_{H}-V_{H}\right)+(1-p)\left(K_{L}-V_{H}-Z_{4}+\alpha W\right)>p\left(K_{H}-Z_{1}\right)+(1-p)\left(K_{L}-Z_{3}\right)
$$

From the formula (1)

$$
\begin{aligned}
& p K_{H}-p V_{H}+K_{L}-V_{H}-Z_{4}+\alpha W-p K_{L}+p V_{H}+p Z_{4}-p \alpha W \\
& >p K_{H}-p V_{L}-p Z_{2}+K_{L}-p K_{L}-V_{L}+p V_{L}
\end{aligned}
$$

concludes that:

$$
V_{H}<p Z_{2}+V_{L}+(1-p)\left(\alpha W-Z_{4}\right)
$$

From the formula (2):

$$
\begin{aligned}
& p K_{H}-p V_{H}+K_{L}-V_{H}-Z_{4}+\alpha W-p K_{L}+p V_{H}+p Z_{4}-p \alpha W \\
& >p K_{H}-p Z_{1}+K_{L}-p K_{L}-Z_{3}+p Z_{3}
\end{aligned}
$$

Introduction:

$$
V_{H}<p Z_{1}+(1-p)\left(Z_{3}+\alpha W-Z_{4}\right)
$$

From the formula (3)-(4):

$$
\begin{aligned}
& p Z_{2}+V_{L}+(1-p)\left(\alpha W-Z_{4}\right)-p Z_{1}-(1-p)\left(Z_{3}+\alpha W-Z_{4}\right) \\
& =p\left(Z_{2}-Z_{1}\right)+V_{L}-(1-p) Z_{3}
\end{aligned}
$$

From the parameters previously set, we can see that:

$$
Z_{2}-Z_{1}<0, p>0,1-p>0, Z_{3}>0
$$

So, $p\left(Z_{2}-Z_{1}\right)+V_{L}<(1-p) Z_{3}$. (This is because the $V_{L}$ is not enough to make up for the difference between the $Z_{3}$ and the $Z_{2}-Z_{1}$ ) 
So

$$
p Z_{2}+V_{L}+(1-p)\left(\alpha W-Z_{4}\right)<p Z_{1}+(1-p)\left(Z_{3}+\alpha W-Z_{4}\right)
$$

That is $V_{H}<p Z_{2}+V_{L}+(1-p)\left(\alpha W-Z_{4}\right)$

Therefore, the following results can be obtained:

$$
\text { Government action }=\left\{\begin{array}{lc}
V_{H} & V_{H}<p Z_{2}+V_{2}+(1-p)\left(\alpha W-Z_{4}\right) \\
V_{L} / 0 & \text { or }
\end{array}\right.
$$

In the first stage of the game, the enterprise can predict the government's strategy and its judgment, and get the $V_{H}$ according to its own type.

When $A=H$, take into account $\max \left\{S_{H}+V_{H}, S_{H}+V_{L}, S_{H}\right\}$, obviously, the maximum of $S_{H}+V_{H}$ is established.

When $A=L$, take into account $\max \left\{S_{L}+V_{H}-C-\alpha W, S_{L}+V_{L}-C, S_{L}\right\}$.

And $S_{L}+V_{L}-C>S_{L}$ was established, this is because based on the realistic setting of the parameters, the camouflage cost $C$ is less than subsidy $V_{L}$.

Take into account $S_{L}+V_{H}-C-\alpha W>S_{L}+V_{L}-C$, that is $V_{H}>\alpha W+V_{L}$.

Therefore, two inequalities can be obtained from the above-mentioned discussion

$$
\left\{\begin{array}{l}
V_{H}<p Z_{2}+V_{L}+(1-p)\left(\alpha W-Z_{4}\right) \\
V_{H}>V_{L}+\alpha W
\end{array}\right.
$$

Obviously, when $p=0$, there is no solution to the inequality system.

When $p=1,\left\{\begin{array}{l}V_{H}<Z_{2}+V_{L} \\ V_{H}>\alpha W+V_{L}\end{array}\right.$.

According to the meaning of the previous parameters, $Z_{2}+V_{L}>\alpha W+V_{L}$ is always valid. This is because punishment is far less than the social benefits lost. Therefore, it can be seen that when $0<p<1$ exists, the mixed equilibrium exists.

However, this kind of mixed equilibrium of high subsidy is not conducive to the development of new energy vehicle industry, so if this equilibrium does not exist, then $V_{L}+\alpha W>p Z_{2}+V_{L}+(1-p)\left(\alpha W-Z_{4}\right)$, that is

$$
p\left(Z_{2}-\alpha W\right)+Z_{4}(p-1)<0 .
$$

And because $Z_{4}>0, p-1<0, p>0$.

So, in order to make the constant establishment, then $Z_{2}-\alpha W<0$. According to the significance of the previous parameters, it can be seen that the social benefits of $Z_{2}$ and $Z_{4}$ are relatively immutable, so in order to make the equation valid, it is necessary to increase the $\alpha W$.

In terms of economic significance, the government must pay more attention to the "subsidy defraud" behavior of the new energy vehicle enterprise, strengthen regulation, and increase the probability that subsidy defraud behavior will be discovered. At the same time, we should intensify our punishment and severely punish "subsidy defraud". In addition, the government should strengthen the supervision of subsidy enterprises and improve the camouflage cost of subsidy defraud behavior. Only in this way can we avoid such mixed equilibrium. 


\subsection{Solution and Analysis of Separation Equalization}

Consider the separation and equilibrium, that is, enterprises with high sales apply for high subsidy, enterprises with low sales apply for low subsidy, the government gives high subsidy or low subsidy according to the application of the enterprise.

The strategy of the enterprise is $\left\{\begin{array}{ll}V_{H} & A=H \\ V_{L} & A=L\end{array}\right.$, after the government receives the signal, the posterior probability of inferred from the type of enterprise is $p\left\{A=H \mid V_{H}\right\}=1, \quad p\left\{A=L \mid V_{L}\right\}=1, \quad p\left\{A=L \mid V_{H}\right\}=0$.

The game tree is shown in the following figure:

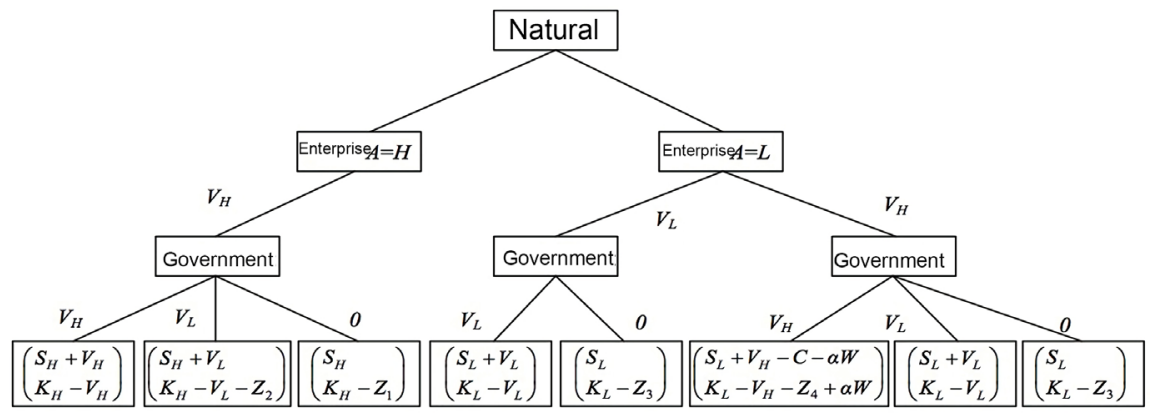

In the second stage of the game, the government receives signal formation inference. $p\left\{A=H \mid V_{H}\right\}=1, \quad p\left\{A=L \mid V_{L}\right\}=1$, choose action $\left\{V_{H}, V_{L}, 0\right\}$ to maximize your expected benefits.

For the high subsidy $V_{H}$, consider the $\max \left\{K_{H}-V_{H}, K_{H}-V_{L}-Z_{2}, K_{H}-Z_{1}\right\}$, and it is easy to know that the necessary and sufficient condition for the government to select a high subsidy $V_{H}$ is $K_{H}-V_{H}>K_{H}-V_{L}-Z_{2}$ and $K_{H}-V_{H}>K_{H}-Z_{1}$. According to the above-mentioned parameters, the above equation is established.

For low subsidy $V_{L}$, considering $\max \left\{K_{L}-V_{L}, K_{L}-Z_{3}, K_{L}-V_{H}-Z_{4}+\alpha W\right\}$, we know that the necessary and sufficient condition for the government to choose low subsidy $V_{L}$ are $K_{L}-V_{L}>K_{L}-Z_{3}, K_{L}-V_{L}>K_{L}-V_{H}-Z_{4}+\alpha W$.

It is easy to know the parameters established by the previous text, and $K_{L}-V_{L}>K_{L}-Z_{3}$ has been established. Therefore, consider $K_{L}-V_{L}>K_{L}-V_{H}-Z_{4}+\alpha W$, that is $\left(V_{L}-V_{H}\right)<\left(Z_{4}-\alpha W\right)$.

Because $V_{L}-V_{H}<0$, therefore, to make the equation set up, it must be $\alpha W>Z_{4}$, that is, the government's supervision and punishment must be big.

In the first stage of the game, new energy vehicle enterprises expect the government's strategy and judgment, according to their own type, choose action $\left\{V_{H}, V_{L}\right\}$ to maximize their expected income.

For $A=H$ new energy vehicle, it has only the option of applying for a high subsidy $V_{H}$, and the $S_{H}+V_{H}>S_{H}+V_{L}>S_{H}$, so the $A=H$ new energy vehicle will definitely choose to apply for a high subsidy $V_{H}$, and the government will definitely give it a high subsidy $V_{H} \cdot A=L$ new energy vehicle enterprises can apply for $\left\{V_{H}, V_{L}\right\}$ two subsidy selection strategies. In order for $A=L$ 
enterprises to apply for low subsidy $V_{L}$,

$$
\max \left\{S_{L}+V_{L}, S_{L}+V_{H}-C-\alpha W, S_{L}+V_{L}-C, S_{L}\right\}
$$

should be considered. For this equilibrium to be established, you must $S_{L}+V_{L}>S_{L}+V_{H}-C-\alpha W$, that is $C+\alpha W>V_{H}-V_{L}$.

In other words, the government must step up its surveillance and penalties so that the sum of the costs of disguise and "subsidy defraud" is greater than the difference between high subsidy and low subsidy. In this way, the enterprise will give up the "subsidy defraud" behavior because of the problem of revenue. Achieve the separation equilibrium of high sales enterprises applying for high subsidy, sales, low sales enterprises applying for low subsidy.

\section{Countermeasures and Suggestions}

In this paper, the signal game model is used to abstract the process of new energy vehicle enterprises applying for subsidy and the government giving subsidy, and the relevant equilibrium solutions are obtained by using the model. The results show that the separation equilibrium is the optimal solution of the whole signal game model. In other words, high sales enterprises apply for high subsidy, while the low sales enterprises apply for low subsidy; The key condition to realize the separation equilibrium is that the sum of the camouflage cost and the punishment of "subsidy defraud" is greater than the difference between high subsidy and low subsidy.

Due to the asymmetry of information, it is possible for government departments to misjudge what kind of subsidy to issue. At this time, if the high sales enterprise applies for high subsidy, and the government only gives low subsidy or refuses to give subsidy, which will have a great impact on the enthusiasm of enterprises and is not conducive to the development of new energy vehicle industry. As a result, the government should issue subsidy as far as possible and avoid such a situation.

In summary, this paper puts forward the following suggestions for the formulation and implementation of new energy vehicle subsidies policy:

1) Realize the diversification of subsidy mode, and we should implement subsidy. to new energy vehicle enterprises in many ways, enrich the way the government subsidy, not a single cash subsidy. For example, strengthen government procurement, give priority to new energy vehicle as the procurement category of government official vehicles, and do a good job of taking the lead in demonstration.

2) Increase the punishment for "subsidy defraud" behavior. The government should strengthen the punishment of "subsidy defraud" behavior and establish a strict punishment system: For example, the subsidy defraud amount of the enterprise is used as the boundary to divide the severity of the "subsidy defraud" behavior of the enterprise. Once the subsidy defraud behavior is serious, in addition to a huge fine, enterprises can also be disqualified from production.

3) Perfect the government subsidy supervision system and establish a perfect 
enterprise revenue and tax supervision mechanism. Make up false material purchase, vehicle production and sales and other original vouchers and records for most enterprises, and make up subsidy defraud, for fictitious sales business. Government department should improve the corresponding revenue and tax supervision mechanism and appoint special people to carry out on-the-spot supervision in order to put an end to the behavior of enterprises to carry out subsidy defraud through fictional sales business.

\section{Conclusions}

In this paper, the signal game model is used to abstract the process of subsidy and the government to issue subsidy, the decision-making choice of the enterprise and the government is studied theoretically, and the following conclusions are drawn:

1) Mixed equilibrium, that is, high/low sales companies apply for high subsidy; it is not perfect for the government to choose to give such a balance to high subsidy.

2) Separation equilibrium, in other words, enterprises with high sales volume apply for high subsidy, and enterprises with low sales volume apply for low subsidy, and the government gives high or low subscription with the enterprise application which is the perfect balance point, and the necessary condition for its existence is $C+\alpha W>V_{H}-V_{L}$. As a result, it can be seen that the subsidy's design should be about $C$ and $\alpha W$ in order to improve the efficiency of the government subsidy.

In order to increase the cost of falsifying $C$, the government must formulate a detailed review mechanism to improve the relevant norms of revenue and tax monitoring, so that low-sales enterprises cannot easily take advantage of the gap and defraud subsidy by falsifying sales vouchers.

In order to improve the $\alpha W$, on the one hand, it is necessary to increase the supervision and the possibility that the "subsidy defraud" behavior of the enterprise will be discovered; on the other hand, it is necessary to increase the punishment of the "subsidy defraud" behavior. On the premise of formulating a perfect revenue and tax review mechanism, the government should strictly review the energy automobile enterprises, and once the "subsidy defraud" behavior is found, it should seriously deal with it.

\section{Funding}

This paper is supported by the key projects of Jiangsu University Philosophy Society Foundation (2014 ZDIXM038, 2017 ZDTXM017, 2017 ZDIXM046, 2018 SJZDI118), the National Natural Science Foundation (7187 4073), and the $\mathrm{Hu}-$ manities and Social Sciences Research Foundation of the Ministry of Education (16YJC630133).

\section{Conflicts of Interest}

The authors declare no conflicts of interest regarding the publication of this paper. 


\section{References}

[1] Hajforoosh, S., Masoum, M.A.S. and Islam, S.M. (2015) Real-Time Charging Coordination of Plug-In Electric Vehicles Based on Hybrid Fuzzy Discrete Particle Swarm Optimization. Electric Power Systems Research, 128, 19-29. https://doi.org/10.1016/j.epsr.2015.06.019

[2] El Nozahy, M.S. and Salama, M.M.A. (2014) Studying the Feasibility of Charging Plug-In Hybrid Electric Vehicles Using Photovoltaic Electricity in Residential Distribution Systems. Electric Power Systems Research, 110, 133-143. https://doi.org/10.1016/j.epsr.2014.01.012

[3] Mona, I., Samir, J. and Geneviève, W. (2016) Nonlinear Autoregressive Neural Network in an Energy Management Strategy for Battery Ultra-Capacitor Hybrid Electrical Vehicles. Electric Power Systems Research, 136, 262-269. https://doi.org/10.1016/j.epsr.2016.03.005

[4] Keles, D., Wietschel, M., Möst, D. and Rentz, O. (2008) Market Penetration of Fuel Cell Vehicles-Analysis Based on Agent Behaviour. International Journal of Hydrogen Energy, 33, 1630-1642. https://doi.org/10.1016/j.ijhydene.2008.04.061

[5] Romano, R.E. (1989) Aspects of R\&D Subsidization. Quarterly Journal of Economics, 104, 863-873. https://doi.org/10.2307/2937871

[6] Li, L. (2018) Research on the Impact of Government R\&D Subsidies on Technological Innovation Output of New Energy Automobile Industry. Research on Science and Technology Management, 38, 160-166.

[7] Shao, S., Yang, K. and Liang, J. (2018) Government Subsidies, R\&D Incentives and Innovation of New Energy Vehicles. Scientific and Technological Progress and Countermeasure, 35, 69-75.

[8] Ma, L., Zhong, W.J. and Mei, E. (2018) Research on Subsidy Strategy of New Energy Automobile Industry Chain Based on the Demand of Sustainability. System Engineering Theory and Practice, 38, 759-767.

[9] Zhong, T.Y. and Du, R. (2015) Research on New Energy Vehicle Subsidy Strategy Based on Game Theory. Management Science in China, 23, 817-822.

[10] Cao, F.S. and Wu, D. (2015) Analysis of New Energy Vehicle R\&D Subsidies Based on Signal Game. Research on Science and Technology Management, 35, 21-25.

[11] Wang, T. and Miao, X.M. (2013) Game Research on New Energy Vehicle R\&D Subsidies in China. Soft Science, 27, 29-32.

[12] Cao, G.H. and Yang, J.J. (2016) Evolutionary Game Study on Consumer's Purchasing Behavior of New Energy Vehicles under Government Subsidies. Inquiry into Economic Issues, 28, 1-9.

[13] Xie, M., Pong, S.L. and Peng, J. (2016) Government Subsidies, New Energy Vehicle Market Value and Enterprise R\&D Investment: An Empirical Analysis Based on Exchange Options and Evolutionary Game Theory. Investment Research, 35, 15-25.

[14] Sun, H.X. and Lu, H.R. (2018) Evolutionary Game Analysis of Government and Enterprise in the Post-Subsidy Era of New Energy Vehicles. Soft Science, 32, 24-29.

[15] Hu, Z.P. (2017) Signal Game Analysis between Government and Enterprise under New Energy Vehicle Subsidy Policy. Resource Development and Market, No. 5, 64-67.

[16] Liu, M.J. (2017) Research on Government Subsidies for New Energy Vehicles Based on Signal Game. Economist, No. 3, 58-59. 